\title{
Ageing: A Growing Challenge
}

\author{
M S Flora ${ }^{1}$
}

\begin{abstract}
Elderly population needs economic support including food, clothing, medical care, and housing as well as cultural support. In view of the size of the population, scarcity of resources, poverty, insufficient health facilities and absence of strong social security, ageing is going to be a major problem for Bangladesh. Preparing for an elderly population "old age" and "ill-health" are inseparable entities to general people. To ensure medical care services separate ward or unit in a hospital should be established for elderly people. "Age-friendly
\end{abstract}

\section{Introduction}

Ageing is a biological phenomenon and refers to a slow imperceptible, progressive degenerative process advancing with chronological age, leading to increased functional deterioration and vulnerability, ultimately culminating in extinction of life. Ageing often refers simply to the process of growing older. It is a biological reality, which (despite medical interventions) has its own dynamic, and is largely beyond human control. Although, there is no internationally accepted age bracket for defining the elderly population, people aged 60 years or above are considered as elderly in most gerontological literature. It is also subject to the constructions by which each society makes sense of old age. In developed societies, chronological age plays a paramount role and the age of 65 , roughly equivalent to retirement age, is said to be the beginning of old age. But in developing countries, chronological age has little importance in defining old age. The age of 60 years is a realistic statistical definition for ageing in Asian and Pacific regions, particularly taking into account average retirement age, legislation, health conditions and so on. Elderly population in the context of Bangladesh has been defined as those who have reached 60 years of age.

It is projected that, by 2020, there will be one billion elderly persons ( $\geq 65$ years) in the world, $71 \%$ of whom will live in low-income countries1. UN also stated that the world is experiencing an age-quake. Every month, one million people reach 60 years of age. ${ }^{2}$ Bangladesh is currently undergoing both epidemiologic and demo

graphic transitions, where the decline in both fertility and mortality rates in early life have resulted in increased life expectancy. ${ }^{3}$ A small proportion (around 6\%) of the total population of Bangladesh constitutes the elderly population, but the absolute number of them is quite significant (about 7.2 million) and the rate of their increase is fairly high. The elderly population (aged 60 years and above) in

1. Dr. Meerjady Sabrina Flora, Associate Professor of Epidemiology NIPSOM. e-mail: meerflora@yahoo.com
Principles for PHC Centres" serve as a tool to increase provider awareness and empower older users of PHC centers. There is need for change in the attitude of not only community and the government but also the people. The elderly should be considered not as a burden to society rather their valuable experience should be utilized fruitfully and it should be the responsibility of the society and the government to impart an improved and effective quality of life to them in return for their lifelong dedicated service towards their children and the nation. Bangladesh in 1911, 1951, 1981 and 1991 were 1.37, $1.86,4.90$ and 6.05 millions respectively and the projected figures for 2000, 2015 and 2025 are 7.25, 12.05 and 17.62 millions. The number of elderly persons in Bangladesh was projected to double from 7.8 million in 2001 to 16.2 million by $2025 .^{4}$ This change in population characteristics will have serious consequences on society as well as on the overall socio-economic development of the country.

\section{Social and Economic Implications of Aging}

Most of the elderly people in Bangladesh live in rural areas where health and recreation facilities are very limited. The majority of them are illiterate; economic facilities and job opportunities are limited. More than half of the elderly are widowed, divorced or single. A large proportion of elderly men are still in labor force both in rural and urban areas. 5,6

Population ageing is already having major consequences and implications in all areas of life, and will continue to do so. In the economic area, population ageing will affect economic growth, savings, investment and consumption, labour markets, pensions, taxation and the transfer of wealth, property and care from one generation to another. Furthermore, most of them are seriously suffering from some basic human needs-related challenges, viz. lack of minimum income and employment opportunities, extreme poverty, illness accompanied by absence of proper health/medical care, food and nutrition, living arrangements, isolation, exclusion, loneliness, negligence, psychosocial and cultural complexities, etc.

Further, older women suffer from multiple disadvantages resulting from biases to gender, widowhood and old age. Women, particularly widows, who are without living sons or who live alone, are considered to be particularly at risk of economic destitution, social isolation, poor health and death. ${ }^{7,8}$ The support system for older men and women differ. The older women's dependency on their families will be higher than that of older men. Marital status is an important determinant of where older persons reside, of their support system, and their individual well-being. This 
risk increases for women who have no assets for survival, such as education, possessions or social status. ${ }^{9,10}$ The vulner ability when compounded by falling health, disability and widowhood makes the elderly women the most defenceless in the Bangladesh context. ${ }^{11-13}$ With the meagre earnings, the poorer segments of the population have in many instances to sell their property to meet their ordinary day to day expenses. Most elderly people, therefore, have to depend almost entirely on family support during their later years. ${ }^{14}$

Most of the elderly people in Bangladesh suffer from some basic human problems, viz poor financial support, senile diseases and absence of proper health and medicare facilities, exclusion and negligence, deprivation and socio-economic insecurity. ${ }^{6}$

Elderly are highly dependent on others for food, clothing, shelter and healthcare. Sometimes they show total faith and dependence on supernatural power and religion. The elderly urban poor, however, have some access to general urban facilities. But they are worse-off in terms of support and assistance from neighbours and community organisations, while in rural areas, the elderly poor get some sympathy and assistance from near and distant relatives or neighbouring well-to-do families.

The aged persons in an average Bangladeshi family are often treated as a burden. Many old men are often seen begging in streets or asking for charity. Not a few are seen in risky work, despite their broken health. Old people live in frustration and suffer from illness and pains without care and company.

\section{Health problems}

Individuals of 60 years and above age are prone to develop certain diseases and ailments which are uncommon in younger age groups. The disorders are of two types: Age dependent, which occurs as a direct consequence of physiological senescence with least possibility of treatment or control, and age related, which are more prevalent in the advanced life which can be prevented. ${ }^{15,1}$

Chronic diseases, by nature, will accumulate with ageing and present as multiple morbidities. Multimorbidity is defined as simultaneous occurrence of several adverse medical conditions in the same person. More than half of elderly had multiple medical conditions, and $84 \%$ had at least one condition. On average, women had more medical conditions than men ( 1.87 vs $1.27, \mathrm{p}<0.0001)$. The most common disorders were arthritis (57.5\%) and hypertension (38.7\%). ${ }^{16}$ Another study found that almost 97 percent elderly suffer some sort of health problems. This prevalence is higher for females than their male counterparts. As can be seen from table 1 that the most common health problems are eye problem (45 percent), weakness (41 percent), arthritis (39 percent), high blood pressure (21 percent $)^{17}$. However, in order to overcome old age health problems, not everyone has access to proper health care facilities due to ignorance, lack of family support, easy accessibility to health care facilities, financial constraints, etc. In comparison to urban areas, access to health care services is limited in rural areas. ${ }^{6}$

Among male elderly, about 43 percent were seen to be self accompanied while going to treatment. On the contrary, female elderly used to accompany by their sons (40 percent) or daughter (16 percent) in higher percentage as compared to their male counterpart. Son as well as daughter in law also play most vital role during looking after their elderly parents at the time of illness. ${ }^{17}$

Multiple factors influence elderly people's choice and use of health care services. The perceived severity of old people's health problems is a key factor affecting healthseeking behaviour. Family members in this study are reported to play an important role in the dynamics of seeking health care by the elderly individuals. socioeconomic status is a strong determinant of health-seeking behaviour even among the elderly. ${ }^{18}$

In Western societies, elderly persons are more likely than younger adults to suffer from malnutrition. A variety of functional, psychological, economic and social factors result in poor diet, qualitatively and quantitatively, that negatively influences the nutritional status of older people. Malnourishment in the older population is also reported to be a consequence of inadequate food intake, underlying illnesses, gender (with women being at higher risk) and economic vulnerability.

About $50 \%$ of the elderly people in a Bangladeshi study suffered from chronic energy deficiency (CED). According to MNA categorisation, the prevalence of PEM and risk of malnutrition in this sample was $26 \%$ and $62 \%$, respectively. Mini Nutritional Assessment of rural elderly people in Bangladesh: the impact of demographic, socioeconomic and health factors. ${ }^{19}$

About $69.3 \%$ percent of the respondents had memory problem. and $64 \%$ feel anxiety or loneliness. ${ }^{2}$

Emergency situations are increasing worldwide and older people remain one of the most seriously affected groups. Yet, the needs and contributions of older people are generally overlooked by humanitarian organizations in terms of policy and practice. ${ }^{20}$

\section{Care of elderly}

The process of development tends to bring rapid changes in social behaviour and institutions, which might have adverse implications for the care and well being of elderly persons. ${ }^{14}$

Currently, two types of care and service systems are available in Bangladesh for the elderly people - traditional or indigenous, and modern. Modern services are offered by both governmental and non-governmental initiatives. Traditional services include care by the family or relatives. Bangladesh has a long cultural and religious tradition of looking after the elderly and it is expected that families and communities will care for their own elderly 
members. But rapid socio-economic and demographic transformations, mass poverty, changing social and religious values, influence of western culture, and other factors, have broken down the traditional extended family and community care system. The findings of a village study conducted in Manikgonj and Rajshahi areas, especially in rural areas, show that community services for the elderly, are greatly lacking. ${ }^{21}$

Government programmes designed for the aged are mainly in the form of pensions, introduced since 1924, but available only for a handful of retired government and industrial employees. In mid 1998, the government introduced a new pension programme 'bayaska bhata' (allowance for the aged), under which the 10 poorest and the most vulnerable old persons (five men and five women) of each union/ward are given a monthly allowance of Tk 100 each. In the current fiscal year (FY 201112), budgetary allocation of Tk. 891 crore has been proposed for 24.75 lac elderly people under the Old Age Allowance (OAA) programme. Although the OAA programme has been beneficial for the poor elderly people, there is a lack of clarity, accountability and proper monitoring -- along with corruption and nepotism -- in the selection process of the elderly. However, the existing allowances or programmes may help some of the elderly population, but most of them remain outside the programmes. Furthermore, some receive pension after retirement from their job, but their number is negligible. ${ }^{22}$ A few non-government organizations have programmes directed specifically at old people. However, their services are confined to outdoor and indoor Medicare, maintenance of old home, recreation facilities for the old people and seminars, workshops, training, research and publication activities. Old-age homes have become popular in urban Bangladesh. Bangladesh Association for the Aged and Institute of Geriatric Medicine are the oldest and largest of all organisations working for the wellbeing of the elderly since 1960. Some universities are expanding their curricula to include courses that focus on ageing. The United Nations (UN) International Day of Older Persons is celebrated on October 1 each year as a special day for the older persons worldwide. Like many other countries, Bangladesh also observes the day with different programmes and activities.

\section{"Age-friendly" primary health care}

World Health Organization in collaboration with stakeholders, is developing a global response to integrate older people's needs and contributions in humanitarian assessments, programmes and interventions. WHO's "agefriendly" primary health care project aims to sensitize and educate PHC providers about the specific needs of their older clients. "Age-friendly Principles for PHC Centres" serve as a tool to increase provider awareness and empower older users of PHC centers. PHC is essential health care made accessible at a cost the country and com munity can afford with methods that are practical, scientifi cally sound and socially acceptable. Primary health care must be accessible and "friendly" to persons of all ages.

The Age-friendly PHC symbol stands for action in three major areas: - improving the attitudes, education and training of health care providers so that they can assess and treat conditions that afflict older persons and empower them to remain healthy

- adapting PHC management systems to the needs of older persons

- making physical access easier for older persons who may have mobility, vision or hearing impairments. ${ }^{23}$

\section{Steps Forward}

There is need for change in the attitude of not only community and the government but also the people. The elderly should be considered not as a burden to society rather their valuable experience should be utilized fruitfully and it should be the responsibility of the society and the government to impart an improved and effective quality of life to them in return for their lifelong dedicated service towards their children and the nation. It is high time that the Bangladeshi policy makers give due importance to the forthcoming age wave. The government should make an earnest and accelerated attempt to bring about reforms in the living arrangements regarding elder abuse and design a suitable social security system and improve the health care facilities for the elderly. The government should realize the importance of geriatrics and make strong efforts to incorporate it in the curricula of the existing and the future Public Health and Medical Institutions in this country. ${ }^{24}$ A study supports the hypothesis that utilizing existing health care structures and providing training to health care providers, the demand for basic gerontological services can be met successfully. ${ }^{21}$

"The potential of older persons is a powerful basis for future development. This enables society to rely increasingly on the skills, experience and wisdom of older persons, not only to take the lead in their own betterment but also to participate actively in that of society as a whole". 25

Further, social engagement should be made for the elderly people in accordance with their physical and mental fitness, educational qualification, needs and preferences. To ensure medical care services separate ward or unit in a hospital should be established for elderly people.

Elderly persons should be involved in the development and implementation of programs and policies according to their minimum needs. The national health system should allocate adequate resources and adopt design strategies to prevent disease. $^{26}$ 


\section{References}

1. Solomons NW. Health and ageing. In: Flores R, Gillepsie S, editors. Health and nutrition: emerging and reemerging issues in developing countries. Washington D.C.: International Food Policy Research Institute, 2001. $3 \mathrm{p}$.

2. Uddin MT, Chowdhury MAI, Islam MN and Baher GU. Status of elderly people of Bangladesh: Health perspective. Proc. Pakistan Acad. Sci. 2010; 47(3):181-189.

3. Population summary for Bangladesh international data base. Washington DC: US Census Bureau, 2010. (http://www.census.gov/population/international/ data/idb/country.php accessed on 27 June 2011).

4. Bangladesh Bureau of Statistics. Population census 2001: preliminary report. Dhaka: Bangladesh Bureau of Statistics, 2009,p43.

5. Abedin S. Population aging in Bangladesh. Issues and Perspectives, Summary of the Country Paper, ESCP, Asian Popultion Studies Series, No. 145; 1996.

6. Begum MS. Geriatric health problems and health care seeking practice among elderly people attending one selected geriatric hospital. Bangladesh J Physiol Pharmacol 2007; 23 (1\&2) : 20-24.

7. Kabir M, Haque M, and Chaklader H. Mainstreaming ageing in health: Will it be possible. Paper presented in the International conference on Mainstreaming ageing in health system and rural development, Held in Dhaka, November, 29-30, 2005.

8. Abedin S. Living and care arrangements of the elderly in Bangladesh. The elderly contemporary Issues: Bangladesh Association of Gerontology. 2003.

9. Sattar MA. A socio economic and health status of the elderly, Bangladesh, 2001. The elderly contemporary Issues: Bangladesh Association of Gerontology. 2003.

10. Chang TP. Implication of changing family structure on old age support in the ESCAP Region. Asia Pacific Population Journal, Vol. 7 NO. 2, ESCAP, Bangkok. 1992.).

11. Sattar MA. Epidemiology of disability of the elderly, Bangladesh. The elderly contemporary Issues: Bangladesh Association of Gerontology. 2003.

12. Audinarayana N, Kavitha N. Factors influencing physical assistance and care to the aged in Tamil Nadu, India: An empirical investigation. The elderly contemporary Issues: Bangladesh Association of Gerontology. 2003.
13. Chen MA, Dreze J. Widowhood and well being in rural North India. In: Gupta DM, Chen LC, Krishman TN, eds. Women's health in India risk and vulnerability. Oxford University Press, 1998.

14. Kabir M. Demographic and Economic Consequences of Aging in Bangladesh.

http:/www.cpd-bangladesh.org/publications/cunfpa3.html

15. Ali MY. Textbook of community medicine and public health. 3rd ed. Dhaka: RKH Publishers; 1999.

16. Khanam MA, Streatfield PK, Kabir ZN, Qiu C, Cornelius C, and Wahlin A. Prevalence and Patterns of Multi-morbidity among Elderly People in Rural Bangladesh: A Cross-sectional Study. J Health Popul Nutr 2011 Aug; 29(4):406-414.

17. Kalam IMS, Khan HTA. Morbidities among older people in Bangladesh: Evidence from an ageing survey. BRAC University Journal, vol. III, no.2, 2006, pp. 75-83.

18. Biswas P, Kabir ZN, Nilsson J \& Zaman S. Dynamics of Health Care Seeking Behaviour of Elderly People in Rural Bangladesh. International Journal of Ageing and Later Life, 2006 1(1): 69-89.

19. Kabir ZN, Ferdous T, Cederholm T, Khanam MA, Streatfied K and Wahlin A. Public Health Nutrition: 9(8), 968-974.

20. WHO. Emergencies and Older People. http://www.who.int/topics/ageing/en/. accessed on 24.02.2012.

21. Tareque MI. Future Appeal of Geriatrics in Bangladesh. University of Rajshahi.

22. Rahman KMM. Preparing for an elderly population. The Daily Star, Tuesday, October 4, 2011.

23. World Health Organization. Active ageing: Towards age-friendly primary health care. World Health Organization 2004. France.

24. World Health Organization. Aging and Life course. http://www.who.int/topics/ageing/en/ accessed on 24.02.2012.

25. From: Resolution 1, Political Declaration and Madrid International Plan of Action on Ageing, 2002

26. Rahman KMM. Unnayan Onneshan policy brief on present social context and elderly population in Bangladesh. 